CORRECTION

\title{
Correction to: Focused Revision: Policy statement on folic acid and neural tube defects
}

Priya Prasad, Mari Mori and Helga V. Toriello; ACMG Professional Practice and Guidelines Committee ${ }^{1 *}$

Genetics in Medicine (2021) 23:2469; https://doi.org/10.1038/s41436-021-01299-3

Correction to: Genetics in Medicine (2021); https://doi.org/10.1038/ s41436-021-01226-6; Article published online 06 July 2021

Priya Prasad, Mari Mori and Helga V. Toriello; ACMG Professional Practice and Guidelines Committee

Addendum to: "Policy statement on folic acid and neural tube defects". Helga V. Toriello, PhD; ACMG Professional Practice and Guidelines Committee Genetics in Medicine 13:593-596 (2011); https://doi.org/10.1097/GIM.0b013e31821d4188, published online 05 May 2011.

For the online author affiliations:

Priya Prasad, MD, Department of Obstetrics and Gynecology, Wayne State University, Detroit, MI, USA

Mari Mori, MD, Nationwide Children's Hospital and The Ohio State University, Columbus, $\mathrm{OH}$, USA

Helga V. Toriello, PhD, Department of Pediatrics and Human Development, Michigan State University, East Lansing, MI, USA

Correspondence: ACMG (documents@acmg.net)

Due to a typesetting error, the following corrections were unfortunately omitted:

$2^{\text {nd }}$ paragraph should read:

Since the publication of the original article in 2011, a nonsystematic review of the literature for updated information on the role of folic acid supplementation in decreasing the prevalence of neural tube defects (NTDs) was done through PubMed and websites of various national health-care organizations, e.g., Centers for Disease Control and Prevention (CDC), National Center on Birth Defects and Developmental Disabilities (NCBDDD), and the US Preventive Services Task Force (USPSTF).

$3^{\text {rd }}$ paragraph $1^{\text {st }}$ sentence should read:

Since 2011, multiple medical and public health organizations have reiterated the recommendation of universal folic acid prophylaxis of $400 \mu \mathrm{g}(0.4 \mathrm{mg})$ daily in all women of childbearing age to prevent the incidence of NTDs in fetuses. $5^{\text {th }}$ paragraph $2^{\text {nd }}$ sentence should read:

It aims to reduce the death and lifelong disability due to NTDs by increasing the intake of folic acid to at least $400 \mu \mathrm{g}(0.4 \mathrm{mg})$ per day in all reproductive-age women.

$11^{\text {th }}$ paragraph $1^{\text {st }}$ sentence should read:

A Cochrane meta-analysis showed that higher doses of folate supplementation ( $>400 \mu \mathrm{g}$ or $>0.4 \mathrm{mg}$ ) with or without additional vitamins and minerals do not have any effect on the prevalence or recurrence of NTDs.

$13^{\text {th }}$ paragraph $1^{\text {st }}$ and $2^{\text {nd }}$ sentences should read:

While folic acid's preventive role is well established, avoidance of drugs that increase the risk of fetal NTDs, like the methotrexate or antiseizure medications (e.g., valproic acid or carbamazepine), should be considered during pregnancy, if clinically safe. Some other micronutrients that have been investigated to have a preventive role in fetal NTDs include thiamine, betaine, riboflavin, vitamin B6, vitamin C, vitamin E, niacin, iron, retinol, vitamin A, and choline.

AMERICAN COLLEGE OF MEDICAL GENETICS AND GENOMICS RECOMMENDATIONS point 2 should read:

High-risk women are recommended to take a higher dose, $4,000 \mu \mathrm{g}(4 \mathrm{mg})$ of daily folic acid supplementation at least 12 weeks prior to conception, with continuation of reduced folic acid supplementation dose of $400 \mu \mathrm{g}(0.4 \mathrm{mg})$ after completion of 12 weeks gestation. Some criteria in defining high-risk status include (but are not limited to) personal, family, or prior pregnancy history of neural tube defects; type 1 diabetes mellitus; or exposure to high-risk medications during early pregnancy.

Point 3 should read:

In spite of patient compliance with supplementation, some fetal neural tube defects are of multifactorial or monogenic etiology, and cannot be completely prevented.

The original article has been corrected. 